\title{
Stereotactic radiotherapy in intrahepatic cholangiocarcinoma: A systematic review
}

\author{
SILVIA BISELLO ${ }^{1,2}$, ANNA CHIARA CAMILLETTI $^{1}$, FEDERICA BERTINI ${ }^{1,2}$, MILLY BUWENGE $^{1,2}$, \\ ALESSANDRA ARCELLI $^{1,2}{ }^{1}$, GABRIELLA MACCHIA ${ }^{3}$, FRANCESCO DEODATO ${ }^{3}$, SAVINO CILLA ${ }^{4}$, \\ GIANCARLO MATTIUCCI ${ }^{5}$, ROSA AUTORINO ${ }^{5}$, GIOVANNI BRANDI ${ }^{6}$, LIDIA STRIGARI ${ }^{7}$, \\ SILVIA CAMMELLI ${ }^{1,2^{*}}$ and ALESSIO G. MORGANTI ${ }^{1,2^{*}}$
}

\author{
${ }^{1}$ Radiation Oncology, IRCCS Azienda Ospedaliero-Universitaria di Bologna; ${ }^{2}$ Radiation Oncology Center, \\ Department of Experimental, Diagnostic, and Specialty Medicine, Alma Mater Studiorum Bologna University, I-40138 Bologna; \\ ${ }^{3}$ Radiotherapy Unit and ${ }^{4}$ Medical Physic Unit, Gemelli Molise Hospital, Università Cattolica del Sacro Cuore, \\ I-86100 Campobasso; ${ }^{5}$ Fondazione Policlinico Universitario A. Gemelli IRCCS, UOC di Radioterapia, \\ Dipartimento di Scienze Radiologiche, Radioterapiche ed Ematologiche, I-00168 Rome; ${ }^{6}$ Department of \\ Medical and Surgical Sciences, University of Bologna, S. Orsola-Malpighi Hospital; ${ }^{7}$ Medical Physics, \\ IRCCS Azienda Ospedaliero-Universitaria di Bologna, I-40138 Bologna, Italy
}

Received November 21, 2020; Accepted April 1, 2021

DOI: $10.3892 / \mathrm{mco} .2021 .2314$

\begin{abstract}
Among biliary tract cancers, intrahepatic cholangiocarcinoma (ICC) has different characteristics compared with those in other sites. Current guidelines suggest several treatment options for ICC, including stereotactic body radiation therapy (SBRT). However, the role of SBRT in locally advanced ICC is unclear. The aim of the present study was to present a systematic review on the efficacy and safety of SBRT in ICC. A systematic review based on the PRISMA methodology was performed. Only papers reporting outcomes in terms of overall survival (OS) after SBRT in inoperable patients with ICC were included. Secondary aims were local control (LC), progression-free survival (PFS) and treatment-related toxicity. Six papers (145 patients) were included in the present analysis. SBRT was frequently used as a salvage treatment, since $28.6-66.7 \%$ of patients received previous systemic or local treatments. The median SBRT dose was 45 Gy delivered in 3-5 fractions. The median follow-up was 16 months, and median OS time was 14 months (range, 10-48 months). In one of the included studies, SBRT was significantly superior in terms of OS compared with both
\end{abstract}

Correspondence to: Dr Silvia Bisello, Radiation Oncology Center, Department of Experimental, Diagnostic, and Specialty Medicine, Alma Mater Studiorum Bologna University, Via Albertoni 15, I-40138 Bologna, Italy

E-mail: silvia.bisello11@gmail.com

*Contributed equally

Key words: stereotactic body radiation therapy, intrahepatic cholangiocarcinoma, systematic review chemoradiation and trans-arterial-radio-embolization. The 1-year LC rate was $85 \%$ in one study, and 1-year PFS rates were 50 and $68 \%$ in two studies, respectively. Toxicity was generally not reported in detail or was reported including other sites of biliary cancers. Overall, limited evidence was available on the efficacy of SBRT in ICC, which should be further investigated in prospective studies with a larger number of patients. However, based on the available data, SBRT seems to produce similar results compared with other ICC treatments, with the advantage of being a very short and non-invasive therapy. Therefore, SBRT should be considered in selected patients with ICC.

\section{Introduction}

Intrahepatic cholangiocarcinoma (ICC) is an aggressive disease representing the second most common liver malignancy (1). The incidence of ICC is increasing worlwide (2). Surgery is considered a potential option with an overall 5 -year survival of about $25-30 \%$. $(3,4)$. Gemcitabine-based chemotherapy (CT) represents the standard therapy in unresectable or metastatic biliary cancers with reported median overall survival (OS) of approximately 12 months $(5,6)$ Particularly, in case of unresectable ICC, both CT or concurrent chemoradiation (CRT) $(7,8)$ are treatment options.

Currently, different local therapies are available for inoperable ICC. The role of trans-arterial chemo-embolization (TACE) has been investigated (9). A meta-analysis on TACE in ICC treatment has been recently published, demonstrating a survival benefit compared to standard systemic therapies, with a good toxicity profile (10) Similarly, radiofrequency ablation resulted an effective treatment option in unresectable ICC. In fact, it was investigated in a systematic review and meta-analysis, reported 82 and 47\% 1-year and 3-year survival rates, respectively (11). 
Stereotactic body radiation therapy (SBRT) is a modern radiotherapy technique delivering ablative radiation doses while sparing the surrounding normal tissues. Despite surrounding organs at risk (OAR) and particularly liver radiosensitivity, SBRT has been considered as a possible therapeutic option in inoperable ICC. Two systematic reviews explored the role of SBRT in cholangiocarcinoma, but systematic reviews specifically addressed to ICC are lacking $(12,13)$. However, the latter have different characteristics compared to tumors in other sites of the biliary tract, both in terms of routes of spread and clinical management. Therefore, even considering the scarce availability of clear guidelines in this setting, we considered it important to analyze the role of this technique (effective in other gastrointestinal neoplasms, such as HCC and pancreatic carcinomas) in the specific field of intrahepatic biliary carcinomas. The aim of this analysis is to present a systematic review of the available literature in the setting of SBRT in ICC.

\section{Materials and methods}

Inclusion criteria. We included in this analysis prospective and retrospective studies reporting OS after SBRT in inoperable ICC. Only English language written papers were considered. Only studies enrolling at least 10 patients with inoperable, non-metastatic, primary, or recurrent ICC were considered. Papers including hepatocellular carcinoma (HCC) patients were considered only if results on subjects with ICC were reported separately. Studies regarding SBRT planned and performed with any technique and device were included in the analysis even if preceded or followed by systemic treatments or other local therapies.

Studies on adjuvant SBRT after radical surgery were excluded. Analyses on preclinical models, planning studies, study protocols, case reports, letters and commentaries, editorials, systematic reviews, and meta-analyses were excluded. Primary endpoint of the analysis was OS. Secondary endpoints were local control (LC), progression-free survival (PFS), and treatment related toxicity.

Literature search strategy. A systematic search was performed on PubMed database on June 1st 2020 including papers published from the earliest date until 31st May 2020. The following search strategy was used: ('cholangiocarcinoma' OR 'cholangiocarcinomas' OR ('intrahepatic' AND 'cholangiocarcinoma') OR 'intrahepatic cholangiocarcinoma') AND (radiosurgery OR 'stereotactic body radiotherapy' OR 'stereotactic body radiation therapy' OR 'stereotactic body radiosurgery' OR 'stereotactic radiotherapy' OR 'stereotactic radiation therapy' OR 'stereotactic radiosurgery' OR stereotaxis OR stereotaxic OR sbrt OR sbrs OR sabr OR 'stereotactic ablative'). The analysis was based on the PRISMA methodology (14).

From the first search on PubMed, title, abstracts, and keywords were independently analyzed by two authors (ACC, FB). Any disagreement was solved by the senior author (RA). A second search based on previous reviews and meta-analyses was performed by two other authors (SB, AA). Full-text evaluation based on the above-mentioned inclusion criteria was independently carried out by the latter two authors. Data on tumor, treatments characteristic, and outcomes were separately collected by two authors (SB and FB), with the supervision of AA. Any disagreement was resolved by a consensus-based discussion with the 2 senior authors ( $\mathrm{SiC}$ and $\mathrm{MB}$ ). Draft correction and critical revision were subsequently performed by all the author, as expressed below.

\section{Results}

Search result. Ninety-three papers were identified from PubMed. Other 74 papers were identified by checking the references list. After duplicates removal, based on a first screening of titles and abstracts, 47 records were excluded. Forty-six papers were subjected to full-text evaluation and 40 were excluded for the reasons described in Fig. 1. Only 6 papers met our inclusion criteria. The flowchart of papers selection is detailed in Fig. 1.

Literature review. Shen et al (15) published the results of a prospective analysis on 28 patients with locally advanced, non-metastatic ICC. All patients underwent SBRT (median prescribed dose: $45 \mathrm{~Gy}$ ), delivered in three to five fractions using a robotic linear accelerator. Median OS and PFS were 15 and 11 months, respectively. A total of 15 patients (53.7\%) manifested grade $\geq 3$ acute toxicity. A higher overall response rate was recorded in patients receiving a biological effective dose (BED) >100 Gy (52.4 vs. 0.0\%, $\mathrm{P}=0.023$ ).

Weiner et al (16) published the results of a phase I/II trial on SBRT in patients with unresectable HCC or ICC. Twelve patients had ICC and two had a bi-phenotypic disease. Median dose was 55 Gy delivered in 5 fractions. With a median follow-up of 8.8 months, median and 1-year OS were 13.2 months and $51.0 \%$, respectively. Seventeen patients (65.4\%) showed grade $\geq 3$ acute toxicity in the whole population (HCC and ICC patients).

Klein et al (17) reported a prospective assessment of quality of life in patients with liver tumors treated with SBRT (24-60 Gy in 6 fractions). Physical and functional items were recorded during and after treatment. Median OS was 12.1 months in the ICC sub-group (20 patients).

Jung et al (18) retrospectively analyzed 58 patients with primary or recurrent intra- or extra-hepatic cholangiocarcinoma treated with SBRT. Thirty-three patients had ICC. Considering the whole population included in the analysis, 91\% (53/58) of patient received SBRT alone (median dose: $45 \mathrm{~Gy}$ in 3-5 fractions) while five patients (9\%) received external beam radiotherapy plus SBRT boost (15 to $18 \mathrm{~Gy}$ in a single fraction). With a median follow-up of 10 months, 1-year OS and PFS were 45 and 26\%, respectively. Two patients from the whole population experienced grade 3 acute toxicity. During follow-up, four patients showed grade 4 late toxicity and two patients with cholangitis and bile duct stenosis required hospitalization. Considering only patients with ICC, median OS was 10 months and actuarial 1- and 2-year OS were 39.0 and $18.0 \%$, respectively.

Sebastian et al (19) retrospectively analyzed 141 patients with inoperable non-metastatic ICC treated with SBRT (27 patients), or TARE (60 patients), or CRT (54 patients). With a median follow up of 17 months, median OS was 48 months in the SBRT group, while median OS in TARE and CRT groups 


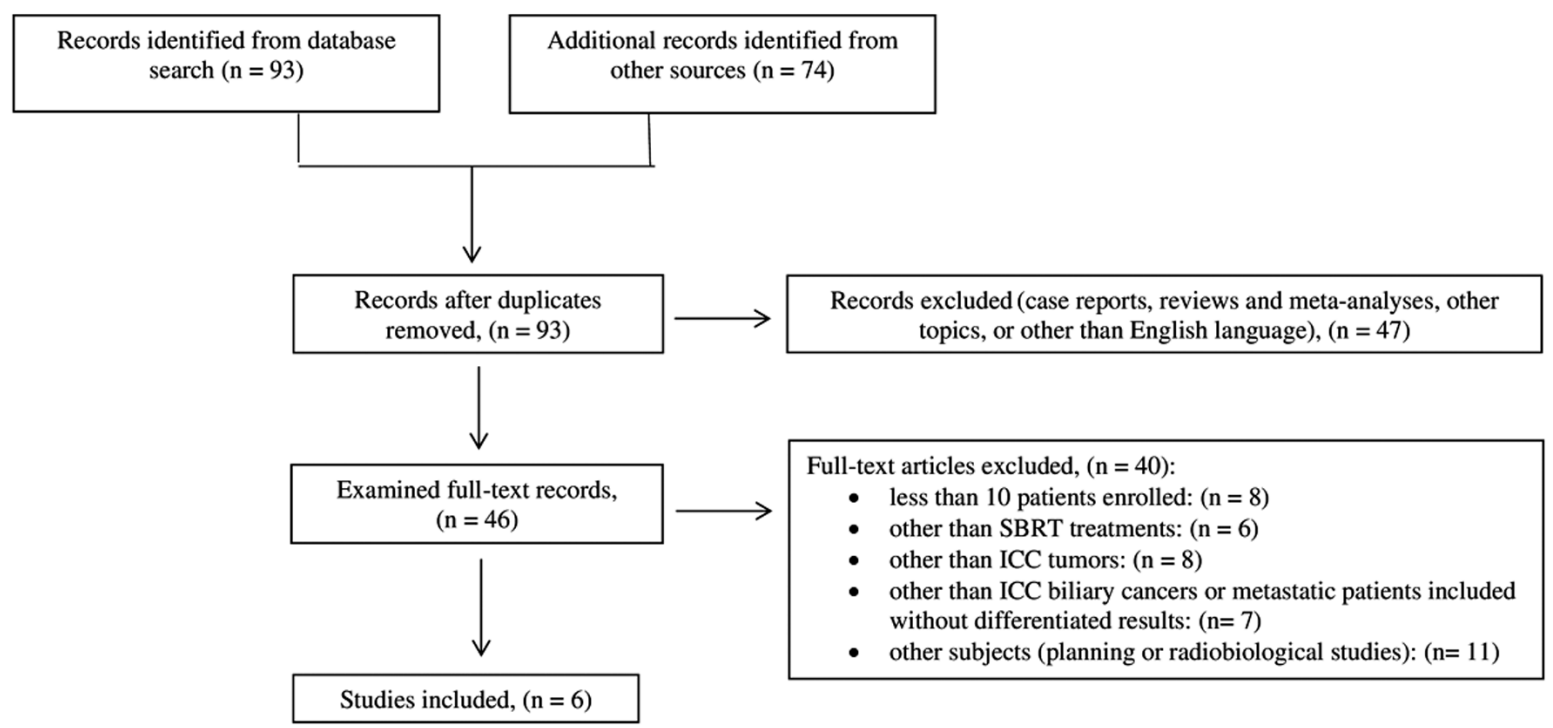

Figure 1. Flowchart of paper selection. After an initial evaluation and removal of duplicates, 93 studies were first selected. Only English-written papers reporting the outcomes of $\geq 10$ patients with unresectable ICC were considered. Outcomes must be referred to SBRT for ICC only. If other diseases or techniques were involved, results must be expressed separately. ICC, intrahepatic cholangiocarcinoma; SBRT, stereotactic body radiation therapy.

were 20 and 14 months, respectively. At multivariate analysis, after propensity weighting adjustment, SBRT was correlated with higher OS compared to CRT $(\mathrm{P}<0.0001)$ and TARE $(\mathrm{P}<0.019)$.

Kozak et al (20) retrospectively collected data on 40 patients treated with SBRT for unresectable intrahepatic (25 patients) or hilar (15 patients) cholangiocarcinoma. For the entire group of patients, $25 \%$ were previously treated with CT, $20.0 \%$ with surgery, $7.5 \%$ with radiofrequency ablation, and $12.5 \%$ with TACE. Median dose was $40 \mathrm{~Gy}$ (range: 26-50) in five fractions. In ICC patients, with a median follow-up of 18 months, median OS was 23 months while in-field local failure and regional failure rates were 40 and $8 \%$, respectively. Considering the whole group, both acute and late grade $\geq 3$ hepatobiliary toxicity were recorded in 17 patients.

Analysis of selected studies. Six studies were included in this analysis reporting data on 145 patients. Four studies were retrospective $(15,18-20)$ one was prospective $(17)$, and one was a phase I/II trial (16). Patients were treated between 2003 and 2017. Studies' characteristics are shown in Table I.

Median follow-up was reported in five studies $(15,16,18-20)$ and ranged between 8.8 and 18.0 months (median: 16 months). In two studies $(15,19)$ ICC characteristics were described in detail. In one report, treated lesions were classified as solitary or multiple and as central or peripheric (15). The same paper reported the disease stage as follows: Stage II: $21.4 \%$, stage III: $67.9 \%$, and stage IVA: $10.7 \%$ (15). Another paper reported the tumor stages as follows: $\mathrm{T}_{1}: 59.3 \%, \mathrm{~T}_{2}: 25.9 \%, \mathrm{~T}_{3}: 11.1 \%$, and $\mathrm{T}_{4}: 3.7 \%$ (19). In one study a $15.0 \%$ rate of patients with nodal involvement was reported (20).

Most patients included in this analysis were previously treated with local or systemic therapies. In one trial $28.6 \%$ of patients were previously treated with TACE (15). Two studies enrolled patients previously treated with CT in $66.7 \%$ (16) and $40.7 \%$ (19) of cases, respectively. Another paper reported on patients who received several previous therapies: CT $(24.0 \%)$, surgery $(20.0 \%)$, radiofrequency ablation $(7.5 \%)$, and TACE (12.5\%) (20).

Table II synthesizes SBRT planning and delivery characteristics. In three studies, the planning target volume (PTV) was defined as the gross tumor volume (GTV) plus $5 \mathrm{~mm}$ margin (15-17), while in two studies, the PTV was defined as the internal target volume (ITV) plus $2-4 \mathrm{~mm}$ margin $(18,20)$. Three studies reported details on dose prescription $(15,16,18)$. The $95 \%$ isodose line had to cover $95 \%$ of the PTV in 2 studies $(15,16)$, while in one study the $92-99 \%$ isodose line had to cover $95 \%$ of PTV (18).

Median prescribed dose was reported in five studies $(15,16,18-20)$, ranging between 45 and 55 Gy (median 45 Gy), delivered in 3-5 fractions. The biological equivalent dose (BED) was reported in 3 studies and ranged between 85.5 and 99.0 Gy (median: 86.0 Gy) $(15,16,18)$.

Only one study reported actuarial LC data, with 85 and $71.0 \%$ 1- and 2-year LC rates, respectively (18). Moreover, one study reported 40 and $8 \%$ local and regional failure crude rates. Respectively (20). Two papers reported 1-year and median PFS. One-year PFS was 50\% (15) and 68\% (16) while median PFS was 11 (15) and 24.7 months (16).

Actuarial OS was reported in three studies with 1-year rates ranging between 39 and 57\% (median value 51\%) $(15,16,18)$. Furthermore, two-year OS rates were $32 \%$ (15) and 18\% (18) in two studies. Median OS was reported in all papers and ranged between 10 and 48 months (median: 14 months) (15-20). Toxicity was generally not described in detail. One paper reported a broad range of grade $\geq 3$ gastrointestinal and hematological toxicities while three papers reported toxicity related to the entire cohort $(16,18,20)$. Two of these papers $(16,18)$ reported grade $\geq 3$ acute toxicity in $3.4 \%$ (18) and $65.4 \%$ (16) of patients and grade $\geq 3$ late toxicity in $6.9 \%$ (18) and $69.2 \%$ (16) of patients, respectively. Another paper reported grade $\geq 3$ acute and late hepatobiliary toxicity, both recorded in $42.5 \%$ of cases (20). 
Table I. Characteristics of the studies included in the systematic review.

\begin{tabular}{|c|c|c|c|c|c|c|c|}
\hline $\begin{array}{l}\text { Author, } \\
\text { year }\end{array}$ & $\begin{array}{l}\text { Study } \\
\text { design }\end{array}$ & $\begin{array}{l}\text { Accrual } \\
\text { period }\end{array}$ & $\begin{array}{l}\text { No. of } \\
\text { patients }\end{array}$ & $\begin{array}{l}\text { Median follow- } \\
\text { up (range), } \\
\text { months }\end{array}$ & ICC features, $\%$ & $\begin{array}{c}\text { Treatment } \\
\text { before SBRT, \% }\end{array}$ & (Refs.) \\
\hline Shen et al, 2017 & Retrospective & 2009-2012 & 28 & $16.0(3.0-42.0)$ & $\begin{array}{l}\text { Peripheral lesions: } 78.6 \text {, } \\
\text { Central lesions: } 21.4 \\
\text { Solitary lesions: } 71.4 \\
\text { Multiple lesions: } 28.6 \\
\text { AJCC stage: II } 21.4, \text { III } \\
67.9, \text { IVA } 10.7\end{array}$ & TACE: 28.6 & (15) \\
\hline Weiner et al, 2016 & Phase I-II & 2012-2014 & 12 & $8.8(0.3-33.0)$ & NRS & CHT: 66.7 & (16) \\
\hline Klein et al, 2015 & Prospective & 2003-2011 & 20 & NR & NR & NR & (17) \\
\hline Jung et al, 2014 & Retrospective & $2005-2013$ & 33 & $10.0(1.0-97.0)$ & NRS & NRS & (18) \\
\hline $\begin{array}{l}\text { Sebastian et al, } \\
2019\end{array}$ & Retrospective & 2004-2014 & 27 & $17.0(\mathrm{NR})$ & $\begin{array}{l}\text { AJCC stage: T1 59.3; } \\
\text { T2 25.9; T3 11.1; T4 } 3.7\end{array}$ & CHT: 40.7 & (19) \\
\hline Kozak et al, 2020 & Retrospective & 2003-2017 & 25 & $18.0(\mathrm{NR})$ & Positive nodes: 15.0 & $\begin{array}{l}\text { CHT: } 24.0 \\
\text { Surgery: } 20.0 \\
\text { RFA: } 7.5 \\
\text { TACE: } 12.5\end{array}$ & (20) \\
\hline
\end{tabular}

AJCC, American Joint Committee on Cancer (31); CHT, chemotherapy; ICC, intrahepatic cholangiocarcinoma; NR, not reported; NRS, not reported separately; RFA, radiofrequency ablation; SBRT, stereotactic body radiation therapy; TACE, trans-arterial chemoembolization.

Only two papers reported tumor response $(15,16)$. The first one, according to the RECIST criteria, reported 10.7, 35.7, 42.9 and $10.7 \%$ rates of complete response, partial response, stable disease, and progressive disease, respectively (15). In the other paper, according to European Association for the Study of the Liver criteria, $33.3 \%$ of patients had a radiographic response and $8.3 \%$ had a complete radiographic response (16). Table III summarizes the treatment outcomes.

\section{Discussion}

To the best of our knowledge, this is the first systematic review on SBRT in the treatment of inoperable, non-metastatic, ICC.

ICC is considered as a rare malignancy in the western world and the management of locally advanced disease is still debated. CT is the standard therapy for advanced ICC $(5,6)$ but the prognosis is still poor. SBRT allows the delivery of ablative doses to the tumor with minimal irradiation of the surrounding tissues. For this reason, some researchers have proposed SBRT as a possible therapeutic option in biliary tract cancer $(12,13,21-23)$. Furthermore, the intrahepatic site of these tumours, therefore within an organ with parallel functional organization, generally far from serial organs unlike extrahepatic biliary tumours, makes ICCs particularly suitable to be treated with SBRT.

Our study has obvious limitations. Firstly, the selection of papers led to the evaluation of only 6 studies. More evidence is available on SBRT in HCC. However, we selected only papers on ICC due to the higher liver radiation sensitivity of HCC patients. In fact, the latter often present an impaired liver function or a cirrhotic status that can lead to higher complication rate. In those cases, a more conservative approach in volume definition or dose delivery may be needed.

The majority of these papers had a retrospective design (15,18-20). Moreover, the number of patients enrolled in the various studies was limited (range of patients enrolled, 12-33 patients). Furthermore, several data were lacking thus limiting the possibility to compare the results. Information on the disease stage $(15,19)$ and treatments prior to SBRT $(15,16,19,20)$ was present only in a few of the papers. Finally, the case series were very heterogeneous in terms of patient characteristics, treatment planning and delivery methods, total dose, fractionation, and results evaluation. The latter issue severely limits the possibility of an inherent comparison between the analyzed studies and among SBRT and other treatments results.

However, there are some worth noting considerations from our review. The best median OS (48 months) was reported in the study of Sebastian et al (19). This result can be justified by the favorable tumor stage ( $\mathrm{cT}_{1-2}$ in $85.2 \%$ of patients). Therefore, this data suggests that OS can be particularly favorable in patients with less extensive ICC. In fact, 5/37 patients undergoing SBRT had $>5$ years OS.

From the comparison between the case series with the highest median SBRT dose (55 Gy) (16) and those with the lowest median dose (40 Gy) (20), it can be observed that median OS was 13.2 months in the former and 23 months in the latter. This comparison seems to suggest the lack of a positive correlation between delivered dose and patients outcome. However, this result contrasts with a study on 79 patients with inoperable ICC where a significant relationship between delivered dose and LC and OS was recorded (24). This difference 
Table II. Treatment planning and dose delivery.

\begin{tabular}{|c|c|c|c|c|c|c|c|}
\hline $\begin{array}{l}\text { Author, } \\
\text { year }\end{array}$ & Target definition & $\begin{array}{l}\text { Median GTV } \\
\text { (range), ml }\end{array}$ & Dose prescription & $\begin{array}{c}\text { Median } \\
\text { dose, } \\
\text { Gy/fractions }\end{array}$ & $\begin{array}{c}\text { Dose range, } \\
\text { Gy }\end{array}$ & $\begin{array}{l}\text { Median } \\
\text { BED }_{10 \mathrm{~Gy}} \\
\text { (range) }\end{array}$ & (Refs.) \\
\hline $\begin{array}{l}\text { Shen et al, } \\
2017\end{array}$ & PTV: GTV + 5 mm & NR & $\begin{array}{l}100 \% \text { isodose } \\
\text { line to cover } \\
\text { GTV } 95 \% \text { isodose } \\
\text { line to cover PTV }\end{array}$ & $45 / 3-5$ & $36-54$ & $\begin{array}{c}85.5 \\
(72.0-124.8)\end{array}$ & (15) \\
\hline $\begin{array}{l}\text { Weiner et al, } \\
2016\end{array}$ & PTV: GTV + 5 mm & $107.0(16.9-625.9)^{\mathrm{a}}$ & $\begin{array}{l}95 \% \text { isodose } \\
\text { line to cover } \\
95 \% \text { PTV }\end{array}$ & $55 / 5$ & $40-55$ & $\begin{array}{c}99.0 \\
(72.0-115.5)\end{array}$ & (16) \\
\hline $\begin{array}{l}\text { Klein et al, } \\
2015\end{array}$ & PTV: GTV + 5 mm & NR & NR & $\mathrm{NR} / 6$ & $24-60^{\mathrm{a}}$ & NRS & $(17)$ \\
\hline $\begin{array}{l}\text { Jung et al, } \\
2014\end{array}$ & PTV: ITV + 2-4 mm & $40.0(5.0-1287.0)$ & $\begin{array}{l}70-80 \% \text { isodose } \\
\text { line (Cyber Knife) } \\
92-99 \% \text { isodose } \\
\text { line to cover 95\% } \\
\text { PTV (Rapid Arc) }\end{array}$ & $\begin{array}{c}45 / 3-5^{\mathrm{b}} \\
\text { EBRT + } \\
\text { SBRT } \\
\text { boost, 16/1 }\end{array}$ & $\begin{array}{c}\text { 30-60 } \\
\text { EBRT + } \\
\text { SBRT } \\
\text { boost, 15-18 }\end{array}$ & $\begin{array}{c}86.0 \\
(48.0-150.0)\end{array}$ & (18) \\
\hline $\begin{array}{l}\text { Sebastian et al, } \\
2019\end{array}$ & NR & NR & NR & $45 / 5$ & $40-50$ & NR & (19) \\
\hline $\begin{array}{l}\text { Kozak et al, } \\
2020\end{array}$ & PTV: ITV + 2-3 $\mathrm{mm}^{\mathrm{a}}$ & NR & NR & $40 / 5$ & $26-50^{\mathrm{a}}$ & NR & $(20)$ \\
\hline
\end{tabular}

${ }^{\text {aF }}$ For the whole population included in the analysis; ${ }^{\text {b9 }} \%$ SBRT only, $9 \%$ EBRT + SBRT boost. BED, biologically effective dose; EBRT, external beam radiation therapy; GTV, gross tumour volume; ITV, internal target volume; NR, not reported; NRS, not reported separately; PTV, planning target volume; SBRT, stereotactic body radiation therapy.

can be explained by the use of 15-30 fractions in most patients in the latter study.

In terms of toxicity, an analytical description of acute toxicity has been reported only in the paper by Shen et al (15). Considering gastrointestinal toxicity, two out of 28 enrolled patients had anorexia, one nausea, one vomiting, and one a gastric ulcer (15). This finding seems to suggest a reasonable tolerability of SBRT in this setting, particularly in terms of low gastrointestinal toxicity rates.

Three papers reported the overall percentage of patients with grade $\geq 3$ acute toxicity, with a wide range of incidence (3.4-65.4\%) $(16,18,20)$. It can be observed that the highest acute toxicity rate was observed in the series with the highest median delivered dose (16). Furthermore, in the series with the worst acute toxicity, the median GTV volume was $107.0 \mathrm{ml}(16)$ while in the series with the lower acute toxicity rate, the median PTV volume was $40.0 \mathrm{ml}$ (18). Comparing late toxicity, the rates recorded in the two series were $69.2 \%$ (16) and $6.9 \%$ (18) respectively. Even within the limits of a comparison between different series, these data would suggest a negative impact on toxicity of higher doses and larger irradiated volumes.

Further considerations can be made by comparing the results of our review with those of other treatments of locally advanced ICC. In particular, our analysis showed that ICC patients undergoing SBRT had a median OS of 14.1 months (range, 10-48 months). However, it should be noted that SBRT was frequently used as a salvage treatment, since $28.6-66.7 \%$ of patients received previous systemic or local treatments $(15,16,19,20)$. This may have affected the results recorded in our analysis.
CT is a standard treatment of advanced ICC. In a series of 26 patients with unresectable ICC, median OS was 18.4 months, slightly higher compared to our analysis (25). However, it should be considered that, in that study, CT was used as an up-front treatment while SBRT was often used as a salvage therapy in our analysis. That same publication reported 30.8 months median OS $(\mathrm{P}<0.001)$ in another group of patients undergoing CT plus intrahepatic arterial infusion (25). This data suggests that combinations of systemic and local therapies may improve outcome in patients with advanced ICC.

Concurrent CRT is another therapeutic option for advanced non-metastatic cholangiocarcinoma, and proper target volume definition could achieve good results (26). Median OS was 13.5 months in a retrospective multicentric study on 76 patients with unresectable biliary cancer (8). Moreover, the results on 27 patients with advanced cholangiocarcinoma who underwent CRT +/- brachytherapy boost were reported in another study (27). Median OS was similar (14 months) and the toxicity grade $\geq 3$ rate was $37 \%$. Although separate data for ICC patients were not reported in these studies, the results seem to suggest that outcomes after SBRT are similar to those of CRT, with a clear benefit in terms of shorter treatment duration for SBRT.

Trans-catheter arterial chemoembolization is another treatment for biliary tract cancer. A meta-analysis on unresectable cholangiocarcinoma reported 13.4 months median OS from the time of first treatment. Severe toxicity was recorded in $18.9 \%$ of patients with $0.7 \%$ rate of 30 -days mortality rate (10). Again, there is no clear difference with the results of our analysis on SBRT. 
Table III. Survival outcomes.

\begin{tabular}{|c|c|c|c|c|c|c|c|c|c|c|}
\hline $\begin{array}{l}\text { Author, } \\
\text { year }\end{array}$ & $\begin{array}{c}\mathrm{LC} \\
\text { rate, } \%\end{array}$ & $\begin{array}{l}\mathrm{PSF} \\
\text { rate, } \\
\%\end{array}$ & $\begin{array}{l}\text { Median } \\
\text { PFS } \\
\text { time, } \\
\text { months }\end{array}$ & OS rate, $\%$ & $\begin{array}{l}\text { Median } \\
\text { OS } \\
\text { time, } \\
\text { months }\end{array}$ & $\begin{array}{l}\text { Toxicity } \\
\text { criteria }\end{array}$ & $\begin{array}{c}\text { Acute } \\
\text { toxicity, } \\
\text { grade } \geq 3, \\
\%(n)\end{array}$ & $\begin{array}{c}\text { Late } \\
\text { toxicity, } \\
\text { grade } \geq 3, \\
\%(n)\end{array}$ & $\begin{array}{c}\text { Tumour } \\
\text { response, } \\
\%\end{array}$ & (Refs.) \\
\hline $\begin{array}{l}\text { Shen } \\
\text { et al, } 2017\end{array}$ & NR & $\begin{array}{c}\text { 1-year: } \\
50.0 \\
\text { 2-year: } \\
21.4\end{array}$ & 11.0 & $\begin{array}{l}\text { 1-year: } 57.1 \\
\text { 2-year: } 32.1\end{array}$ & 15.0 & $\begin{array}{c}\text { CTCAE } \\
\text { v. } 4.0\end{array}$ & $\begin{array}{c}\text { Nausea: } 3.6(1) \\
\text { Anorexia: } 7.1(2) \\
\text { Vomiting: } 3.6(1) \\
\text { Gastric } \\
\text { ulcer: } 3.6(1) \\
\text { Altered hepatic } \\
\text { values: } 25.0(7) \\
\text { Haematological } \\
\text { toxicity: } 10.8(3)\end{array}$ & NR & $\begin{array}{c}\text { Complete } \\
\text { response: } 10.7 \\
\text { Partial } \\
\text { response: } 35.7 \\
\text { Stable } \\
\text { disease: } 42.9 \\
\text { Progressive } \\
\text { disease: } 10.7 \\
\text { (RECIST } \\
\text { criteria) }\end{array}$ & (15) \\
\hline $\begin{array}{l}\text { Weiner } \\
\text { et al, } 2016\end{array}$ & NRS & $\begin{array}{c}\text { 1-year: } \\
68.0\end{array}$ & 24.7 & 1-year: 51.0 & 13.2 & $\begin{array}{c}\text { CTCAE } \\
\text { v. } 4.0\end{array}$ & $65.4(17)^{\mathrm{a}}$ & $69.2(18)^{\mathrm{a}}$ & $\begin{array}{l}\text { Radiographic } \\
\text { response: } 33.3 \\
\text { Complete } \\
\text { radiographic } \\
\text { response: } 8.3 \\
\text { (EASL criteria) }\end{array}$ & (16) \\
\hline $\begin{array}{l}\text { Klein } \\
\text { et al, } 2015\end{array}$ & NR & NR & NR & NR & 12.1 & NR & NR & NR & NR & (17) \\
\hline $\begin{array}{l}\text { Jung } \\
\text { et al, } 2014\end{array}$ & $\begin{array}{c}\text { 1-year: } \\
85.0 \\
\text { 2-year: } \\
71.0\end{array}$ & NR & NR & $\begin{array}{l}\text { 1-year: } 39.0 \\
\text { 2-year: } 18.0\end{array}$ & 10.0 & $\begin{array}{c}\text { CTCAE } \\
\text { v.4.0 }\end{array}$ & $3.4(2)^{\mathrm{a}}$ & $6.9(4)^{\mathrm{a}}$ & NR & (18) \\
\hline $\begin{array}{l}\text { Sebastian } \\
\text { et al, } 2019\end{array}$ & NR & NR & NR & NR & 48.0 & NR & NR & NR & NR & (19) \\
\hline $\begin{array}{l}\text { Kozak } \\
\text { et al, } 2020\end{array}$ & $\begin{array}{l}\text { Local } \\
\text { failures: } \\
40.0 \\
\text { Regional } \\
\text { failures: } \\
8.0\end{array}$ & NR & NR & NR & 23.0 & NR & $\begin{array}{c}\text { Hepatobiliary: } \\
42.5(17)^{\mathrm{a}} \\
\text { Non- } \\
\text { hepatobiliary: } \\
2.5(1)^{\mathrm{a}}\end{array}$ & $\begin{array}{c}\text { Hepatobiliary: } \\
42.5(17)^{\mathrm{a}} \\
\text { Non- } \\
\text { hepatobiliary: } \\
2.5(1)^{\mathrm{a}}\end{array}$ & NR & (20) \\
\hline
\end{tabular}

a Data including other sites of biliary cancers. CTCAE, Common Terminology Criteria for Adverse Events (32); EASL, European Association for the Study of the Liver (33); LC, local control; NR, not reported; NRS, not reported separately; OS, overall survival; PFS, progression-free survival; RECIST, Response Evaluation Criteria In Solid Tumours (34).

Similarly, a meta-analysis of 12 studies on radio-embolization with ${ }^{99}$-Ittrium microsphere reported 15.5 months median weighted OS. Also this result is similar to the one of our analysis on SBRT. Toxicity was mainly represented by fatigue (33\%), pain (28\%) and nausea (25\%) (28).

Finally, some recent studies evaluated the potential role of proton beam radiation therapy in cholangiocarcinoma. In a retrospective study on unresectable or locally recurrent ICC, 34 patients were treated with photon-based radiotherapy while 32 patients were treated with protons. Two-year OS was 49 and $65 \%$, respectively. At multivariate analysis, compared to photon-based radiotherapy, there was a trend for improved OS with protons (HR: 0.50; p: 0.05) (29). In another retrospective analysis (30) on 30 patients with unresectable cholangiocarcinoma treated with proton-therapy (median dose: 72.6 cobalt Gy equivalent) median OS was
19.3 months. However, $10 \%$ of patients developed grade $\geq 3$ gastric/duodenal ulcers. This irradiation modality deserves further study in the ICC setting, based on the theoretical advantages of proton therapy in terms of dose distribution. However, the currently available results do not allow a comparison with SBRT.

In conclusion, although other options are available in this setting, preliminary literature data on SBRT in ICC seems to suggest that this treatment could be considered as a possible therapeutic option.

Further studies are needed in this field. These analyzes could be aimed to the: i) assessment of efficacy and tolerability of SBRT in ICC by large and prospective trials; ii) definition of optimal dose, fractionation and GTV to PTV margins in this setting; iii) comparison between SBRT and other ICC local treatments; considering the palliative aim 
of advanced ICC therapies, these studies should include an accurate assessment of treatments impact on quality of life; iv) feasibility and efficacy of combined modality treatments including SBRT (for example: SBRT combined with systemic therapies; SBRT as a boost after concurrent chemoradiation).

\section{Acknowledgements}

The abstract was presented as an electronic poster at the virtual XXX Congresso Nazionale Associazione Italiana Radioterapia Oncologia on 9-12th December 2020.

\section{Funding}

No funding was received.

\section{Availability of data and materials}

The datasets used and/or analyzed during the current study are available from the corresponding author on reasonable request.

\section{Authors' contributions}

SB, MB, GMac, GMat, GB, LS, FD and AGM conceived and organized the study. FB, AC, SB, AA and RA selected the papers and acquired the data. SB, FB, MB, SCa, SCi and AA analysed and interpreted the data. AC, SB, MB, RA, FD, SCi and AGM drafted the manuscript. SCa, FD and $\mathrm{SCi}$ assessed the authenticity of the raw data. SCa, FD, GB, AGM, GMat and GMac critically revised the manuscript for important intellectual content. SB, AGM, MB, FD and SCi discussed and reviewed the latest changes of the manuscript. All authors read and approved the final manuscript.

\section{Ethics approval and consent to participate}

Not applicable.

\section{Patient consent for publication}

Not applicable.

\section{Competing interests}

The authors declare that they have no competing interests.

\section{References}

1. Shaib YH, Davila JA, McGlynn K and El-Serag HB: Rising incidence of intrahepatic cholangiocarcinoma in the United States: A true increase? J Hepatol 40: 472-477, 2004.

2. Saha SK, Zhu AX, Fuchs CS and Brooks GA: Forty-year trends in cholangiocarcinoma incidence in the U.S.: Intrahepatic disease on the rise. Oncologist 21:594-599, 2016.

3. Endo I, Gonen M, Yopp AC, Dalal KM, Zhou Q, Klimstra D, D'Angelica M, dematteo RP, Fong Y, Schwartz L, et al: Intrahepatic cholangiocarcinoma: Rising frequency, improved survival, and determinants of outcome after resection. Ann Surg 248: 84-96, 2008.

4. Chou FF, Sheen-Chen SM, Chen YS, Chen MC and Chen CL: Surgical treatment of cholangiocarcinoma. Hepatogastroenterology 44: 760-765, 1997.
5. Valle JW, Wasan H, Johnson P, Jones E, Dixon L, Swindell R, Baka S, Maraveyas A, Corrie P, Falk S, et al: Gemcitabine alone or in combination with cisplatin in patients with advanced or metastatic cholangiocarcinomas or other biliary tract tumours: A multicentre randomised phase II study- the UK ABC-01 study. Br J Cancer 101: 621-627, 2009.

6. Okusaka T, Nakachi K, Fukutomi A, Mizuno N, Ohkawa S, Funakoshi A, Nagino M, Kondo S, Nagaoka S, Funai J, et al: Gemcitabine alone or in combination with cisplatin in patients with biliary tract cancer: A comparative multicentre study in Japan. Br J Cancer 103: 469-474, 2010.

7. Bisello S, Buwenge M, Zamagni A, Deodato F, Macchia G Alessandra A, Cammelli S, Mattiucci GC, Cellini F and Morganti AG: Chemoradiation in unresectable biliary tract cancer: A systematic review. Hepatol Pancreat Sci 2018.

8. Bisello S, Buwenge M, Palloni A, Autorino R, Cellini F, Macchia G, Deodato F, Cilla S, Brandi G, Tagliaferri L, et al: Radiotherapy or chemoradiation in unresectable biliary cancer: A retrospective study. Anticancer Res 39: 3095-3100, 2019.

9. Zechlinski JJ and Rilling WS: Transarterial therapies for the treatment of intrahepatic cholangiocarcinoma. Semin Intervent Radiol 30: 21-27, 2013.

10. Ray CE Jr, Edwards A, Smith MT, Leong S, Kondo K, Gipson M, Rochon PJ, Gupta R, Messersmith W, Purcell T and Durham J: Metaanalysis of survival, complications, and imaging response following chemotherapy-based transarterial therapy in patients with unresectable intrahepatic cholangiocarcinoma. J Vasc Interv Radiol 24: 1218-1226, 2013.

11. Han K, Ko HK, Kim KW, Won HJ, Shin YM and Kim PN: Radiofrequency ablation in the treatment of unresectable intrahepatic cholangiocarcinoma: Systematic review and meta-analysis. J Vasc Interv Radiol 26: 943-948, 2015.

12. Frakulli R, Buwenge M, Macchia G, Cammelli S, Deodato F, Cilla S, Cellini F, Mattiucci GC, Bisello S, Brandi G, et al: Stereotactic body radiation therapy in cholangiocarcinoma: A systematic review. Br J Radiol 92: 20180688, 2019.

13. Lee J, Yoon WS, Koom WS and Rim CH: Efficacy of stereotactic body radiotherapy for unresectable or recurrent cholangiocarcinoma: A meta-analysis and systematic review. Strahlenther Onkol 195: 93-102, 2019.

14. Hutton B, Salanti G, Caldwell DM, Chaimani A, Schmid CH, Cameron C, Ioannidis JP, Straus S, Thorlund K, Jansen JP, et al: The PRISMA extension statement for reporting of systematic reviews incorporating network meta-analyses of health care interventions: Checklist and explanations. Ann Intern Med 162: 777-784, 2015.

15. Shen ZT, Zhou H, Li AM, Li B, Shen JS and Zhu XX: Clinical outcomes and prognostic factors of stereotactic body radiation therapy for intrahepatic cholangiocarcinoma. Oncotarget 8: 93541-93550, 2017.

16. Weiner AA, Olsen J, Ma D, Dyk P, dewees T, Myerson RJ and Parikh P: Stereotactic body radiotherapy for primary hepatic malignancies-Report of a phase I/II institutional study. Radiother Oncol 121: 79-85, 2016.

17. Klein J, Dawson LA, Jiang H, Kim J, Dinniwell R, Brierley J, Wong R, Lockwood G and Ringash J: Prospective longitudinal assessment of quality of life for liver cancer patients treated with stereotactic body radiation therapy. Int J Radiat Oncol Biol Phys 93: 16-25, 2015.

18. Jung DH, Kim MS, Cho CK, Yoo HJ, Jang WI, Seo YS, Paik EK, Kim KB, Han CJ and Kim SB: Outcomes of stereotactic body radiotherapy for unresectable primary or recurrent cholangiocarcinoma. Radiat Oncol J 32: 163-169, 2014.

19. Sebastian NT, Tan Y, Miller ED, Williams TM and Alexandra Diaz D: Stereotactic body radiation therapy is associated with improved overall survival compared to chemoradiation or radioembolization in the treatment of unresectable intrahepatic cholangiocarcinoma. Clin Transl Radiat Oncol 19: 66-71, 2019.

20. Kozak MM, Toesca DAS, von Eyben R, Pollom EL and Chang DT: Stereotactic body radiation therapy for cholangiocarcinoma: Optimizing locoregional control with elective nodal irradiation. Adv Radiat Oncol 5: 77-84, 2019.

21. Mahadevan A, Dagoglu N, Mancias J, Raven K, Khwaja K, Tseng JF, Ng K, Enzinger P, Miksad R, Bullock A and Evenson A: Stereotactic body radiotherapy (SBRT) for intrahepatic and Hilar cholangiocarcinoma. J Cancer 6: 1099-1104, 2015.

22. Brunner TB, Blanck O, Lewitzki V, Abbasi-Senger N, Momm F, Riesterer O, Duma MN, Wachter S, Baus W, Gerum S, et al: Stereotactic body radiotherapy dose and its impact on local control and overall survival of patients for locally advanced intrahepatic and extrahepatic cholangiocarcinoma. Radiother Oncol 132: 42-47, 2019. 
23. Liu MY, Lo CH, Lin CS, Chao HL, Yang JF, Lin KT, Fan CY, Su YF and Huang WY: Stereotactic ablative radiotherapy for patients with unresectable or medically inoperable cholangiocarcinoma. Tumori 103: 236-241, 2017.

24. Tao R, Krishnan S, Bhosale PR, Javle MM, Aloia TA, Shroff RT, Kaseb AO, Bishop AJ, Swanich CW, Koay EJ, et al: Ablative radiotherapy doses lead to a substantial prolongation of survival in patients with inoperable intrahepatic cholangiocarcinoma: A retrospective dose response analysis. J Clin Oncol 34: 219-226, 2016.

25. Konstantinidis IT, Koerkamp BG, Do RK, Gönen M, Fong Y, Allen PJ, D'Angelica MI, Kingham TP, Dematteo RP, Klimstra DS, et al: Unresectable intrahepatic cholangiocarcinoma: Systemic plus hepatic arterial infusion chemotherapy is associated with longer survival in comparison with systemic chemotherapy alone. Cancer 122: 758-765, 2016.

26. Bisello S, Renzulli M, Buwenge M, Calculli L, Sallustio G, Macchia G, Deodato F, Mattiucci G, Cammelli S, Arcelli A, et al: An atlas for clinical target volume definition, including elective nodal irradiation in definitive radiotherapy of biliary cancer. Oncol Lett 17: 1784-1790, 2019.

27. Autorino R, Mattiucci GC, Ardito F, Balducci M, Deodato F, Macchia G,Mantini G,Perri V,Tringali A, Gambacorta MA, et al: Radiochemotherapy with gemcitabine in unresectable extrahepatic cholangiocarcinoma: Long-term results of a phase II study. Anticancer Res 36: 737-740, 2016

28. Al-Adra DP, Gill RS, Axford SJ, Shi X, Kneteman N and Liau SS Treatment of unresectable intrahepatic cholangiocarcinoma with yttrium-90 radioembolization: A systematic review and pooled analysis. Eur J Surg Oncol 41: 120-127, 2015.

29. Smart AC, Goyal L, Horick N, Petkovska N, Zhu AX, Ferrone CR, Tanabe KK, Allen JN, Drapek LC, Qadan M, et al: Hypofractionated radiation therapy for unresectable/locally recurrent intrahepatic cholangiocarcinoma. Ann Surg Oncol 27: $1122-1129,2020$
30. Hung SP, Huang BS, Hsieh CE, Lee CH, Tsang NM, Chang JT, Chen JS, Chou WC, Tseng JH and Hong JH: Clinical outcomes of patients with unresectable cholangiocarcinoma treated with proton beam therapy. Am J Clin Oncol Cancer Clin Trials 43: 180-186, 2020.

31. Edge BS and Compton CC: American joint committee on cancer: The 7 th edition of the AJCC cancer staging manual and the future of TNM. Ann Surg Oncol 17: 1471-1474, 2010.

32. Trotti A, Colevas AD, Setser A, Rusch V, Jaques D, Budach V, Langer C, Murphy B, Cumberlin R, Coleman CN and Rubin P: CTCAE v3.0: Development of a comprehensive grading system for the adverse effects of cancer treatment. Semin Radiat Oncol 13: 176-181, 2003.

33. Bruix J, Sherman M, Llovet JM, Beaugrand M, Lencioni R, Burroughs AK, Christensen E, Pagliaro L, Colombo M and Rodés J; EASL Panel of Experts on HCC: Clinical management of hepatocellular carcinoma. Conclusions of the Barcelona-2000 EASL conference. European association for the study of the liver. J Hepatol 35: 421-430, 2001.

34. Schwartz LH, Litière S, de Vries E, Ford R, Gwyther S, Mandrekar S, Shankar L, Bogaerts J, Chen A, Dancey J, et al: RECIST 1.1-update and clarification: From the RECIST committee. Eur J Cancer 62: 132-137, 2016.

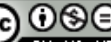

This work is licensed under a Creative Commons Attribution-NonCommercial-NoDerivatives 4.0 International (CC BY-NC-ND 4.0) License. 